\title{
Burnout and its impact on mental health of physicians during the COVID -19 pandemic: A cross-sectional study from South India
}

\author{
Nukala Srikrishna ${ }^{1}$, Archana Vinnakota ${ }^{2 *}$, Singisetti Srinivas ${ }^{3}$, Chilukuri Shvetha ${ }^{4}$, Garapati Venkata Abhilash ${ }^{5}$, \\ Sanapala Vidya ${ }^{6}$, Lakshmana Rao $^{7}$
}

\author{
${ }^{\mathbf{1}}$ Professor \& Head, ${ }^{\mathbf{A}}$ Associate Professor, ${ }^{\mathbf{3}, \mathbf{4}}$ Assistant Professor, ${ }^{\mathbf{5}, \mathbf{6}}$ Senior Resident, ${ }^{\mathbf{7}}$ Assistant Professor cum statistician, \\ ${ }^{1-6}$ Dept. of Psychiatry, GITAM Institute of Medical Sciences and Research, Visakhapatnam, Andhra Pradesh, ${ }^{7}$ Dept. of Community \\ Medicine, Maharaja Institute of Medical Sciences, Vizianagaram, Andhra Pradesh, India
}

*Corresponding Author: Archana Vinnakota

Email: vinnakotaarchana@gmail.com

\begin{abstract}
Background: A large number of doctors are experiencing Burnout during the present COVID-19 pandemic. Excessive workload, uncertainty, longer working hours, work - family conflicts, and difficult working conditions during the pandemic are some of the reasons for physician Burnout. The greatest risk of Burnout is that doctors may feel disconnected with their profession and are more likely to suffer from various mental health issues.

Aim: To assess Burnout and its impact on mental health of physicians during the COVID-19 pandemic.

Materials and Methods: A cross-sectional study was conducted on physicians working at Government designated COVID-19 Hospitals of a city in South India in May 2020. Purposive sampling technique was used in the study. One hundred and eighty eight (188) physicians were included in the study and were given the requisite material and study tools via email, after providing them with information about the study and tools for assessment. Oldenburg Burnout Inventory (OLBI) was used to assess Burnout. Hospital Anxiety and Depression scale (HADS) was used for screening of anxiety and depression in physicians. Chi-square test and Pearson's correlation were used in statistical analysis.

Results: Burnout was noted in $54.3 \%$ of physicians. Anxiety and Depression was seen in $14.9 \%$ and $15.4 \%$ of the physicians respectively. Age, presence of anxiety and depression had a significant association with Burnout. Disengagement group showed a stronger positive correlation with depression, while exhaustion group showed a stronger positive correlation with anxiety.

Conclusion: Burnout, anxiety and depression levels amongst physicians noted in the current study seem to be far less when compared to other existing studies. This could be resultant from better preparedness of physicians for public health crisis compared to other health care workers. The high rates of Burnout, anxiety and depression among physicians during the pandemic highlights the need for designing the appropriate psychological interventions by the healthcare system to support the physicians working in the midst of COVID-19 pandemic and in the post-pandemic era.
\end{abstract}

Keywords: Anxiety, Depression, Disengagement, Doctors, Exhaustion.

\section{Introduction}

The word 'Burn out' was coined by psychologist Herbert Freudenberger. It is a state of extreme mental exhaustion resulting from factors related to one's professional life. The three characteristic features of Burn out are emotional exhaustion, depersonalization and a reduced sense of accomplishment or success. ${ }^{1}$ The COVID-19 pandemic has led to a devastating effect on health care workers, who run the risk of Burnout, with the worry about their own health, fear of infecting family members, managing with limited such as personal protective gears, working in unfamiliar clinical conditions, and, having to make difficult decisions about who should receive critical care when resources such as ventilators are limited in number. ${ }^{2}$

Existing literature on Burnout has focused on the negative consequences of mental health. ${ }^{3}$ An association between Burnout and depression as well as between Burnout and anxiety have been already described in literature..$^{4-7} \mathrm{~A}$ cross sectional study done in China on 1257 health care professionals during the COVID-19 pandemic showed that $50.4 \%$ had depressive symptoms, $34.0 \%$ had insomnia, $44.6 \%$ with anxiety and $71.5 \%$ reported distress. The study highlighted that the healthcare professionals working in the frontline during the pandemic are prone for worse mental health outcomes. ${ }^{8}$ In the present study, the authors have made an attempt to assess Burnout and its psychological impact in physicians during the COVID-19 pandemic.

\section{Materials and Methods}

This was a cross-sectional study conducted on physicians working at Government designated COVID -19 Hospitals of a city in South India in May 2020. Permission was obtained from the Institutional Ethics Committee to conduct this study. Purposive sampling technique was used in the study. 240 physicians were contacted over phone and verbally explained about the study, out of which, 212 physicians expressed their willingness to participate in the study. The willing physicians were provided with participant information sheet, informed consent form, and study questionnaires through email correspondence. The participant information sheet had a statement about the history of prior mental health illnesses which was the only exclusion criterion. Out of 212 physicians, 24 have reported history of prior mental illness and hence, were excluded from the study sample. Thus, final sample of study consisted of 188 physicians. The questionnaires that were included in the study tools comprised of 2 sections: 
i. The first section included sociodemographic characteristics of the physicians.

ii. The second section was a questionnaire that has two scales:

1. Oldenburg Burnout Inventory (OLBI) is a 16-item scale to measure Burn out in physicians from work related adverse experiences, including feelings of disengagement and exhaustion from work. It has two dimensions' disengagement and exhaustion. The reliability of the exhaustion subscale has been found to range from $\alpha=.74$ to $\alpha=.85$, and the reliability of the disengagement subscale from .73 to .85 across various studies. $^{9}$ Each sub scale consists of 8 items, four positively phrased and four negatively phrased items, presented in mixed order. Each item has four responses ranging from 1 (strongly agree) to 4 (strongly disagree). ${ }^{10}$ Cut off score $\geq 2.25$ on exhaustion were considered as having high exhaustion, while scores $\geq 2.1$ on disengagement were considered as high. ${ }^{11}$ Based on the disengagement and exhaustion scores, the four Burn out groups were:

i. Non-Burnout (low disengagement score and low exhaustion score),

ii. Disengaged (high disengagement score and low exhaustion score)

iii. Exhaustion (high exhaustion score and low disengagement score)

iv. Burnout (high disengagement score and high exhaustion score)

2. Hospital Anxiety and Depression scale (HADS) is a self-assessment 14 item scale which has 7 questions on depression and 7 questions on anxiety. ${ }^{12}$ Each item has 4 responses ranging from 0 to 3 . A score of 0 to 7 is normal, 8 to 10 is borderline, while 11 to 21 is considered as clinical caseness. HADS was developed for assessing nonpsychiatric patient's emotional state. It has been previously found that the correlations between the two subscales varied from .40 to .74 (mean .56) and, Cronbach's alpha for HADS-A varied from .68 to .93 (mean.83) and for HADS-D from .67 to .90 (mean.82). ${ }^{13}$

3. Sleep disturbance was assessed with one single question 'Did you experience any sleep disturbance during past 1 week' with 4 responses like Never, Sometimes, Often, Daily.

4. Questions on physical symptoms like Headache, Neck pain, Back pain, Chest pain, Pain abdomen, Nausea, were assessed with yes/no answers. The inclusion of these specific symptoms was based on the common physical symptoms associated with stress and Burnout in literature. ${ }^{14}$

\section{Results}

Statistical analysis was performed by using SPSS-16 version and in MS-Excel 2007. Qualitative variables were expressed as in frequencies and percentages. The data was normally distributed; this was checked with the help of the Kolmogorov Smirnov test. Chi-square test was used for examining the categorical data. Fisher's exact test was used for examining the associations between age groups and Burnout. Karl-Pearson's correlation coefficient was used to explore the relationship between quantitative variables. ANOVA was used to compare the means between more than two groups. For all statistical analysis $\mathrm{p}<0.05$ was considered statistically significant.

\section{Burnout data analysis}

Of 188 physicians, $54.3 \%$ were in the Burnout category (high disengagement and high exhaustion), $6.4 \%$ were in the Exhaustion category (high exhaustion and low disengagement), $17.5 \%$ were in the Disengaged category (high disengagement and low exhaustion), while $21.8 \%$ were in Non-Burnout category (low disengagement and low exhaustion).

\section{Hospital Anxiety and Depression (HADS) data analysis}

Anxiety was noted in $14.9 \%$ and Depression was seen in $15.4 \%$ of the total sample.

Table 1: Associations between socio-demographic characteristics, presence of anxiety and depression in physicians vs four Burnout categories.

\begin{tabular}{|c|c|c|c|c|c|c|c|}
\hline Characteristics & & $\begin{array}{c}\text { Non-Burnout } \\
\mathbf{N}(\%)\end{array}$ & $\begin{array}{c}\text { Disengaged } \\
\mathbf{N}(\%)\end{array}$ & $\begin{array}{c}\text { Exhaustion } \\
\mathbf{N}(\%)\end{array}$ & $\begin{array}{c}\text { Burn out } \\
\mathbf{N}(\%)\end{array}$ & $\begin{array}{c}\text { Total } \\
\text { N }(\%)\end{array}$ & $\begin{array}{c}\mathbf{P} \\
\text { value }\end{array}$ \\
\hline Total & & $41(21.8 \%)$ & $33(17.5 \%)$ & $12(6.4 \%)$ & $102(54.3 \%)$ & $188(100 \%)$ & \\
\hline \multirow{5}{*}{ Age group } & $25-35$ yrs. & 41 & 33 & 12 & 16 & $102(54.3 \%)$ & \multirow{5}{*}{$0.001 *$} \\
\hline & $36-45$ yrs. & 0 & 0 & 0 & 52 & $52(27.7 \%)$ & \\
\hline & $46-55$ yrs. & 0 & 0 & 0 & 18 & $18(9.6 \%)$ & \\
\hline & $56-65$ yrs. & 0 & 0 & 0 & 12 & $12(6.4 \%)$ & \\
\hline & $66-75$ yrs. & 0 & 0 & 0 & 4 & $4(2.1 \%)$ & \\
\hline P Value & & $0.001 *$ & $0.001 *$ & $0.001 *$ & $0.001 *$ & & \\
\hline \multirow{2}{*}{ Gender } & Male & 23 & 15 & 7 & 46 & $91(48.4 \%)$ & \multirow{2}{*}{0.571} \\
\hline & Female & 18 & 18 & 5 & 56 & $97(51.6 \%)$ & \\
\hline P Value & & 0.435 & 0.602 & 0.564 & 0.322 & & \\
\hline \multirow{2}{*}{ HADS Anxiety } & $>=11$ & 3 & 2 & 3 & 20 & $28(14.9 \%)$ & \multirow{2}{*}{$0.024^{*}$} \\
\hline & $<11$ & 38 & 31 & 9 & 82 & $160(85.1 \%)$ & \\
\hline P Value & & $0.001 *$ & $0.001 *$ & 0.083 & $0.001 *$ & & \\
\hline
\end{tabular}




\begin{tabular}{|l|c|c|c|c|c|c|c|}
\hline \multirow{2}{*}{$\begin{array}{l}\text { HADS } \\
\text { Depression }\end{array}$} & $>=11$ & 4 & 2 & 2 & 21 & $29(15.4 \%)$ & \multirow{2}{*}{$0.038^{*}$} \\
\cline { 2 - 8 } P Value & $<11$ & 37 & 31 & 10 & 81 & $159(84.6 \%)$ & \\
\hline
\end{tabular}

${ }^{*} \mathrm{P}$ value $<0.05$ was statistically significant.

Table 2: Pearson's Correlation coefficients between OLBI and HADS scores

\begin{tabular}{|c|c|c|c|c|c|}
\hline & & Disengagement & Exhaustion & Anxiety & Depression \\
\hline \multirow{3}{*}{ Disengagement } & $\mathrm{R}$ & 1 & .761 & .569 & .626 \\
\hline & $P$ value & $0.001 * *$ & $0.001^{* * *}$ & $0.001^{* *}$ & $0.001^{* *}$ \\
\hline & $\mathrm{N}$ & 188 & 188 & 188 & 188 \\
\hline \multirow{3}{*}{ Exhaustion } & $\mathrm{R}$ & .761 & 1 & .686 & .672 \\
\hline & $\mathrm{P}$ value & $0.001^{* *}$ & $0.001 * *$ & $0.001^{* *}$ & $0.001^{* *}$ \\
\hline & $\mathrm{N}$ & 188 & 188 & 188 & 188 \\
\hline \multirow{3}{*}{ Anxiety } & $\mathrm{R}$ & .569 & .686 & 1 & .837 \\
\hline & $\mathrm{P}$ value & $0.001^{* *}$ & $0.001^{* * *}$ & $0.001 * *$ & $0.001^{* *}$ \\
\hline & $\mathrm{N}$ & 188 & 188 & 188 & 188 \\
\hline \multirow{3}{*}{ Depression } & $\mathrm{R}$ & .626 & .672 & .837 & 1 \\
\hline & $P$ value & $0.001^{\text {** }}$ & $0.001^{* * *}$ & $0.001^{* *}$ & $0.001 * *$ \\
\hline & $\mathrm{N}$ & 188 & 188 & 188 & 188 \\
\hline
\end{tabular}

$* * \mathrm{P}<0.01$ was statistically highly significant
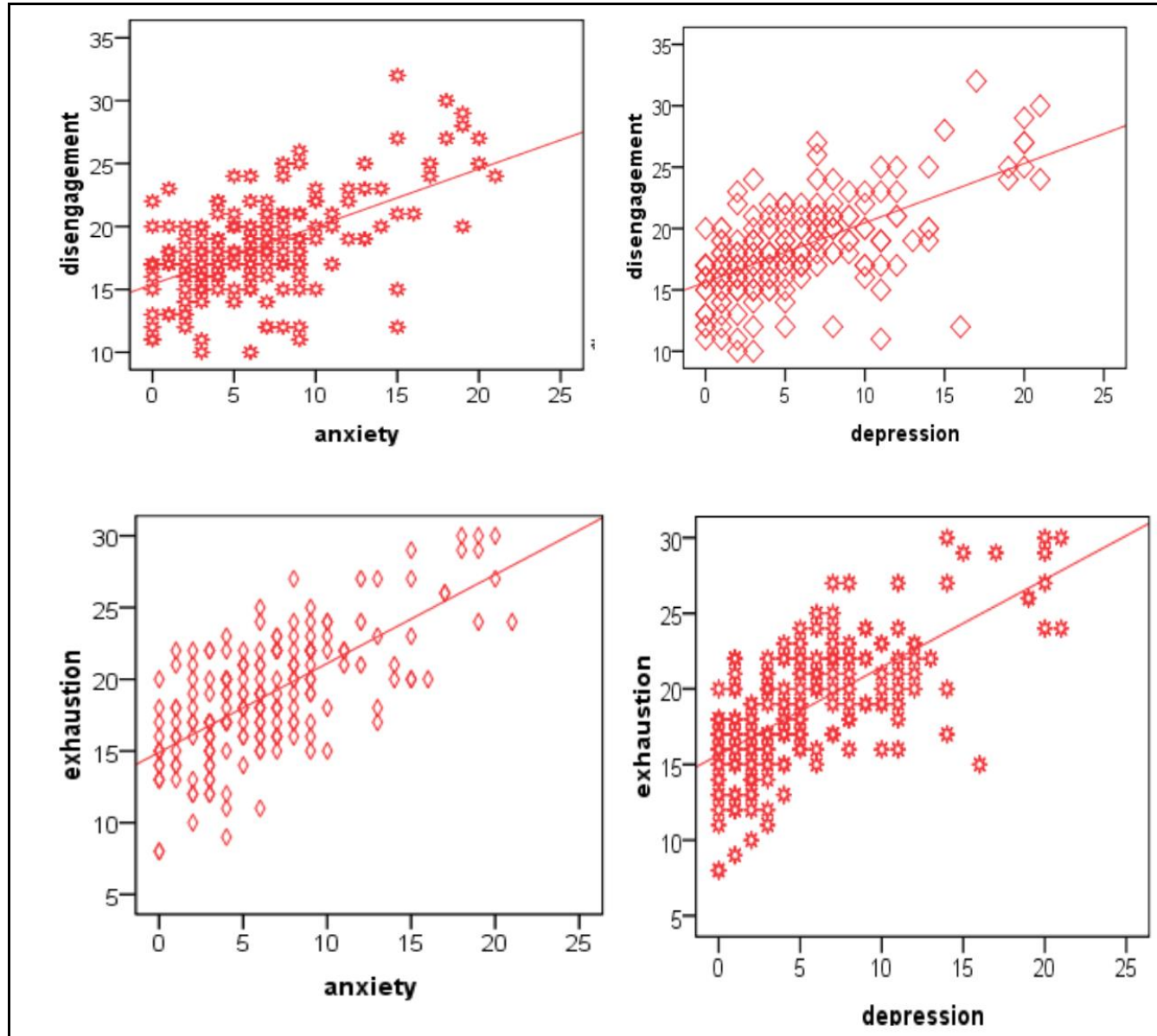

Fig. 1: Scatter plot showing correlation of disengagement, exhaustion vs depression and anxiety 
Table 3: Prevalence of somatic symptoms

\begin{tabular}{|l|c|c|}
\hline Total sample =188 & & $\mathbf{N}(\mathbf{\%})$ \\
\hline \multirow{4}{*}{ Sleep disturbance } & Never & $64(34.0 \%)$ \\
\cline { 2 - 3 } & Sometimes & $81(43.1 \%)$ \\
\cline { 2 - 3 } & Often & $29(15.4 \%)$ \\
\cline { 2 - 3 } & Daily & $14(7.4 \%)$ \\
\hline \multirow{2}{*}{ Headache } & Yes & $74(39.5 \%)$ \\
\cline { 2 - 3 } & No & $114(60.6 \%)$ \\
\hline \multirow{2}{*}{ Neck pain } & Yes & $50(26.6 \%)$ \\
\cline { 2 - 3 } & No & $138(73.4 \%)$ \\
\hline \multirow{2}{*}{ Back pain } & Yes & $72(38.3 \%)$ \\
\hline \multirow{2}{*}{ Chest pain } & No & $116(61.7 \%)$ \\
\hline \multirow{2}{*}{ Pain abdomen } & Yes & $10(5.3 \%)$ \\
\cline { 2 - 3 } & No & $178(94.7 \%)$ \\
\hline \multirow{2}{*}{ Nausea } & Yes & $18(9.6 \%)$ \\
\cline { 2 - 3 } & No & $170(90.4 \%)$ \\
\cline { 2 - 3 } & Yes & $26(13.8 \%)$ \\
\hline
\end{tabular}

Table 1 depicts association between sociodemographic variables of physicians, presence of anxiety and depression vs four Burn out categories. The four Burn out groups were found to have statistically significant association with age, anxiety and depression. The individual domains $p$ value showed that Disengagement, Burnout and Non-Burnout groups were found to be significantly $(\mathrm{p}<0.05)$ associated with HADS anxiety except Exhaustion group.

As shown in Table 2, Pearson's correlation was used to find correlation between disengagement, exhaustion, anxiety and depression scores. While each group correlated significantly and positively with all the other 3 groups $(\mathrm{p}<0.01)$; disengagement showed stronger positive correlation with depression, while exhaustion showed stronger positive correlation with anxiety.

Table 3 shows presence of different somatic symptoms in physicians. As noted, Sleep disturbances was the most frequent somatic symptom, followed by headache, backpain, neck pain, nausea, pain abdomen, and chest pain.

\section{Discussion}

Health care provision can be emotionally and physically challenging leading to high rates of Burn out among health care workers. The serious nature of the profession leaves little margin for mistakes. ${ }^{15,16}$ Tight work schedules with overtime and intrusion into personal and family life, and the stress of dealing with ethical issues and complex decision making for patients, result in professional dissatisfaction. ${ }^{17}$ ${ }^{21}$ All these factors can potentially be worsened by the uncertainty and pressure on resources brought on by a health care crisis such as the COVID pandemic.

Research on practicing physicians have shown high Burnout prevalence rates, with one-third of physicians reporting Burnout at some phase in their careers. ${ }^{22}$ The Burnout observed among physicians in the current study was $54.3 \%$. Studies have shown Burnout rates during their careers, as high as $54.3 \%$ and $45 \%$ among professionals and medical graduates respectively. ${ }^{23-25} \mathrm{~A}$ meta-analysis of
22,778 medical residents in 2019, reported that Burn out was seen in one out of every two residents. ${ }^{26}$ Another study that systematically reviewed mental health presentations in health care workers during pandemics showed prevalence of Burnout in $34 \% .{ }^{27}$ In the current study, higher rates of Burnout were noted in age groups 36-45 yrs. and in female gender. This might be due to the expectations from the healthcare system that young doctors to work in frequent shift duties and for longer working hours as the older age group is thought to be at high risk during the COVID-19 pandemic. The high Burnout rates among female physicians might be due to their efforts in balancing their role in the family and hospital.

Emotional health outcomes like depression, anxiety and stress are found to be associated with Burnout. ${ }^{11,28-30}$ Repeated Burnout among health care workers make them highly vulnerable to various psychological symptoms such as anxiety, depression, sleep disturbance, weakness and lethargy. ${ }^{31}$ Physicians in developing countries are overburdened from shortage of work force, resulting in stress and exhaustion. ${ }^{32}$ In the current study anxiety, depression and sleep disturbances was noted in 14.9\%, $15.4 \%$ and $65.9 \%$ respectively among physicians; whereas a similar study that was done in India during COVID -19 pandemic reported $30.9 \%$ depression and $39.5 \%$ anxiety among doctors. ${ }^{33}$ Another study done on health care workers in china during COVID-19 pandemic reported 50.4\% depression $44.6 \%$ anxiety and $34 \%$ sleep disturbances. ${ }^{8} \mathrm{~A}$ systematic review of 115 studies looking into mental health symptoms in health care workers during pandemics showed presence of fear $(43.7 \%)$, insomnia $(37.9 \%)$, psychological distress $(37.8 \%)$, burnout $(34.4 \%)$, anxiety $(29 \%)$, and depressive symptoms (26.3\%) as the main psychological symptoms. ${ }^{27}$ However, when compared to other studies of anxiety and depression in Indian settings, and amongst health care workers from other countries like China during pandemic situations; Burnout, anxiety and depression levels noted in the current study seem to be far less. This could be resultant from a better preparedness of physicians for public health crisis compared to other health care workers. There could have been other factors like illness severity and complications, physician - patient ratio, communication and resource management at the hospitals. Specific to the present study, the higher percentage of physicians were in the younger age group and this could be another reason for the lower Burn out rates. The psychological resilience among youth could be more compared to middle-aged and elderly. Differences in the physician's working conditions like department / specialty, hours of work, place of work, nature of work, pay and availability of personal protective equipment may have influenced the rates of Burn out.

In the present study, disengagement showed stronger positive correlation with depression, while exhaustion showed stronger positive correlation with anxiety. Similarly Ding et al., study has shown that emotional exhaustion is positively related to anxiety symptoms. ${ }^{34}$ A systematic review analysis by $\mathrm{P}$ Koutsimani et al., has showed 
significant association of Burn out with both depression and anxiety. ${ }^{35}$

Such high rates of mental health symptoms and Burn out among physicians working in COVID hospitals, would also call for interventions such as cognitive behavior therapies, problem solving and mindfulness approaches, and existential therapies, if necessary, through telepsychotherapy, as measures to support physicians working in the midst of COVID-19 pandemic and in the postpandemic era. A systematic review analysis by Clough et al., showed promising results in reducing stress and Burnout among doctors by implementing behavioral and cognitive interventions. ${ }^{36}$ This study highlights the need of the healthcare systems at various levels to act appropriately in designing the working conditions and supportive measures for the physicians who are working relentlessly in managing patients with COVID-19.

There are certain limitations to the present study. The study was limited to COVID hospitals in one particular district and this might not be representative of other hospitals in India. Questionnaires used in the study such as HADS and OLBI have not been validated in an Indian setting. Standard questionnaires were not used for assessing sleep and pain; only single questions related to it were asked. The study questionnaires were circulated through email correspondence which has its own online survey drawbacks and limitations around generalizability. Personality profiles of the practicing physicians were not assessed, which could have given us a better picture of the various physician factors impacting on the levels of Burnout and anxiety and depression. Sociodemographic variables such as marital status, presence of old age persons, children and acquaintance or death due COVID-19 among the family and friends were not included.

Future studies looking into Burnout in physicians with larger sample sizes, and different work settings and specialties are needed. Also, tools to measure Burn-out in an Indian setting and COVID-19 specific situations are further required.

\section{Conclusion}

The levels of Burnout and its impact on mental health amongst physicians noted in our study appears high at first instance. Burnout, anxiety and depression levels noted in the current study seem to be far less compared to other studies. Also, it would be generally expected that the Burn out and mental health symptoms in physicians during pandemic times would be higher than usual. One could hypothesize various reasons for these lower adverse mental health outcomes. High percentage of physicians in the present study were among younger age group and the better preparedness of physicians for public health crisis could be reasons. The study highlights the need for implementing the necessary psychological interventions by the health care system to support the physicians during the COVID-19 pandemic in order to protect them from the adverse mental health consequences of Burnout in their workplace.

\section{Source of Funding}

None.

\section{Conflict of Interest}

None.

\section{Acknowledgement}

All physicians who participated in the study

\section{References}

1. Richelson G. Burn-out: The high cost of high achievement. Garden City, NY: Anchor Press; 1980.

2. Saleh M. Harvard Medical School CME Online. A Double Whammy: The COVID-19 Pandemic and Burnout in Medical Professionals [Internet]. Last updated on 9 April 2020 [cited June 2020]. Available from:

https://leanforward.hms.harvard.edu/2020/04/09/a-doublewhammy-the-covid-19-pandemic-and-Burnout-in-medicalprofessionals

3. Melamed S, Shirom A, Toker S, Berliner S, Shapira I. Burnout and risk of cardiovascular disease: evidence, possible causal paths, and promising research directions. Psychol Bull. 2006;132(3):327-53.

4. Ahola K, Honkonen $\mathrm{T}$, Isometsä $\mathrm{E}$. The relationship between job-related Burnout and depressive disorders--results from the Finnish Health 2000 Study. J Affect Disord. 2005;88(1):55-62.

5. Toppinen-Tanner S, Ojajärvi A, Väänänen A, Kalimo R, Jäppinen P. Burnout as a predictor of medically certified sickleave absences and their diagnosed causes. Behav Med. 2005;31(1):18-27.

6. Wang J. Work stress as a risk factor for major depressive episode(s). Psychol Med. 2005;35(6):865-71.

7. Bargellini A, Barbieri A, Rovesti S, Vivoli R, Roncaglia R, Borella P. Relation between immune variables and Burnout in a sample of physicians. Occup Environ Med. 2000;57(7):4537.

8. Lai J, Ma S, Wang Y, Cai Z, Hu J, Wei N, et al. Factors Associated With Mental Health Outcomes Among Health Care Workers Exposed to Coronavirus Disease 2019. JAMA Netw Open. 2020;3(3):e203976.

9. Halbesleben JR, Demerouti E. The construct validity of an alternative measure of Burnout: Investigating the English translation of the Oldenburg Burnout Inventory. Work Stress. 2005;19(3):208-20.

10. Demerouti E, Mostert K, Bakker AB. Burnout and work engagement: a thorough investigation of the independency of both constructs. J Occup Health Psychol. 2010;15(3):209-22.

11. Peterson U, Demerouti E, Bergström G, Samuelsson M, Asberg M, Nygren A. Burnout and physical and mental health among Swedish healthcare workers. J Adv Nurs. 2008;62(1):84-95.

12. Zigmond AS, Snaith RP. The hospital anxiety and depression scale. Acta Psychiatr Scand. 1983;67(6):361-370.

13. Bjelland I, Dahl AA, Haug TT, Neckelmann D. The validity of the Hospital Anxiety and Depression Scale. An updated literature review. J Psychosom Res. 2002;52(2):69-77.

14. Salvagioni DAJ, Melanda FN, Mesas AE, González AD, Gabani FL, Andrade SM. Physical, psychological and occupational consequences of job Burnout: A systematic review of prospective studies. PLoS One. 2017;12(10):e0185781.

15. Ramirez AJ, Graham J, Richards MA, Cull A, Gregory WM. Mental health of hospital consultants: the effects of stress and satisfaction at work. Lancet. 1996;347(9003):724-8.

16. Familoni OB. An overview of stress in medical practice. Afr Health Sci. 2008;8(1):6-7. 
17. Cooper CL, Rout U, Faragher B. Mental health, job satisfaction, and job stress among general practitioners. BMJ. 1989;298(6670):366-70.

18. Theorell T, Ahlberg-Hulten G, Sigala F, Perski A, Soderholm M, Kallner A, et al. A psychosocial and biomedical comparison between men in six contrasting service occupations. Work Stress. 1990;4(1):51-63.

19. Sutherland VJ, Cooper CL. Identifying distress among general practitioners: predictors of psychological ill-health and job dissatisfaction. Soc Sci Med. 1993;37(5):575-81.

20. Enzer I, Sibbald B. General Practitioners' work satisfaction in 1998, executive summary 13. University of Manchester: NPCRDC. 1999.

21. Coomber S, Todd C, Park G, Baxter P, Firth-Cozens J, Shore S. Stress in UK intensive care unit doctors. Br J Anaesth. 2002;89(6):873-81.

22. Shanafelt TD, Boone S, Tan L, et al. Burnout and satisfaction with work-life balance among US physicians relative to the general US population. Arch Intern Med. 2012;172(18):137785.

23. Bauer J, Stamm A, Virnich K, et al. Correlation between Burnout syndrome and psychological and psychosomatic symptoms among teachers. Int Arch Occup Environ Health. 2006;79(3):199-204.

24. Dyrbye LN, West CP, Satele D, Boone S, Tan L, Sloan J, et al. Burnout among U.S. medical students, residents, and early career physicians relative to the general U.S. population. Acad Med. 2014;89(3):443-51.

25. Lee YY, Medford AR, Halim AS. Burnout in physicians. $J R$ Coll Physicians Edinb. 2015;45(2):104-7.

26. Low ZX, Yeo KA, Sharma VK. Prevalence of Burnout in Medical and Surgical Residents: A Meta-Analysis. Int J Environ Res Public Health. 2019;16(9):1479.

27. Salazar de Pablo G, Vaquerizo-Serrano J, Catalan A, Arango $\mathrm{C}$, Moreno C, Ferre F, et al. Impact of coronavirus syndromes on physical and mental health of health care workers: Systematic review and meta-analysis. J Affect Disord. 2020;275:48-57.

28. Prosser D, Johnson S, Kuipers E, Szmukler G, Bebbington P, Thornicroft G. Mental health, "Burnout' and job satisfaction among hospital and community-based mental health staff. $\mathrm{Br} J$ Psychiatry. 1996;169(3):334-337.
29. Turnipseed DL. Anxiety and Burnout in the health care work environment. Psychological Reports. 1998;82(2):627-42.

30. Bennett S, Plint A, Clifford TJ. Burnout, psychological morbidity, job satisfaction, and stress: a survey of Canadian hospital-based child protection professionals. Arch Dis Child. 2005;90(11):1112-6.

31. Welp A, Meier LL, Manser T. Emotional exhaustion and workload predict clinician-rated and objective patient safety. Front Psychol. 2015; 5:1573.

32. Hamid N, Charkhabi M, Amanollah Nejad M. Relationship between dimensions of Burnout and mental health in physicians of hospitals affiliated in Ahvaz Jundishapur University. J Modr Indus Org Psy. 2011;2(6):9-16.

33. Chatterjee SS, Bhattacharyya R, Bhattacharyya S, Gupta S, Das S, Banerjee BB. Attitude, practice, behavior, and mental health impact of COVID-19 on doctors. Indian J Psychiatry. 2020;62(3):257-65.

34. Ding Y, Qu J, Yu X, Wang S. (The mediating effects of Burnout on the relationship between anxiety symptoms and occupational stress among community healthcare workers in China: a cross-sectional study. PLoS One. 2014;9:e107130.

35. Koutsimani P, Montgomery A, Georganta K. The relationship between burnout, depression, and anxiety: A systematic review and meta-analysis. Front Psychol. 2019;10:284.

36. Clough BA, March S, Chan RJ, Casey LM, Phillips R, Ireland MJ. Psychosocial interventions for managing occupational stress and Burnout among medical doctors: a systematic review. Syst Rev. 2017;6(1):144.

How to cite this article: Srikrishna N, Vinnakota A, Srinivas S, Shvetha C, Abhilash GV, Vidya S, Rao L. Burnout and its impact on mental health of physicians during the COVID -19 pandemic: A cross-sectional study from South India. Telangana J Psychiatry. 2020;6(2):160165. 